\title{
A prospective study of the latero-central glandular pedicle technique as an oncoplastic procedure for medial quadrants breast masses:oncological safety and clinical outcomes Ayman Ahmed Talaat, Ahmad Gamal El Din Osman, Niveen Fathy Al Mahmoudy, Mohammed Mostafa Ali \\ General Surgery Department, Faculty of Medicine, Ain Shams University
}

CORRESPONDING AUTHOR: MOHAMED GLAL, EMAIL: dodigalal2003@yahoo.com

\begin{abstract}
Background: breast cancer, according to national cancer institute, is the most common site of cancer in women in Egypt as it accounts for about 38.8\% of total malignancies among Egyptian females; it is an important cause of mortality among women. For many women with stage 1 or 2 breast cancer, the combination of partial mastectomy and radiation therapy - together referred to as breast- conserving therapy is preferable to total mastectomy because breast conserving surgery survival rates is equivalent to those after mastectomy while preserving the breast. Aim of the work: this study aimed to focus on the latero-central glandular pedicle technique as an oncoplastic procedure for management of medial breast cancer and to assess the technique clinically regarding oncological safety, surgical outcomes and patient satisfaction. Methods: this was a prospective analytical study that included 15 patients aiming to clinically assess the centro-lateral oncoplastic technique for both inner quadrants of breast cancer regarding oncological safety and patient satisfaction. This study was conducted at AinShams University Hospitals. Approval of the Ethical Committee and written informed consent from all participants was obtained. Results: in our study we were able to conduct an excellent cosmetic outcome for a relatively large tumor excisions with $66 \%$ of the cases (10 patients) falling in excellent and very good score groups with mean cosmetic outcome score 4.26 . Another $20 \%$ (3 cases) which fall in good and fair score groups as those two patients noticed asymmetry of the two breasts in front of the mirror as they refused bilateral breast reduction mastopexy. None of our cases have had a poor or an ugly score. Conclusion: the combination of plastic surgery techniques with breast oncology surgery gives the surgeon a new tool for treatment of breast cancer. This approach has enabled us to increase the number and extend the indications of breast conserving surgery with wider margins offering safer oncologic control with more satisfactory cosmetic outcome.
\end{abstract}

\section{Introduction}

The breast is the true mirror of femininity, and it remains in the mind of every one of us as the heart of womanhood, with its role as nourisher, and comforter. These roles evoke the idea of the importance and the affection of this delicate organ has in the minds of women. ${ }^{(1)}$ Breast cancer, according to national cancer institute, is the most common site of cancer in women in Egypt as it accounts for about $38.8 \%$ of total malignancies among Egyptian females; it is an important cause of mortality among women ${ }^{(2)}$.Breast reconstruction is becoming increasingly important due to changes in patient expectations and demand. There is growing recognition that immediate reconstruction in appropriately selected women can combine an oncological and aesthetic procedure in one operation with excellent results. Because most breast surgery is performed by general surgeons, most reconstructions were performed as delayed procedures by plastic surgeons. Increasingly, breast surgery is being performed by breast surgeons trained in oncoplastic techniques who can offer immediate reconstruction with both therapeutic and economic option ${ }^{(3)}$.

The blood supply to the breast skin depends on the subdermal plexus, which is in communication with deeper underlying vessels supplying the breast parenchyma. The blood supply is derived from the internal mammary perforators (most notably the second to fifth perforators), the thoracoacromial artery, the vessels to serratus anterior, the lateral thoracic artery, the terminal branches of the third to eighth intercostal perforators, the superomedial perforator supply from the internal mammary vessels is particularly robust and accounts for some $60 \%$ of the total breast blood supply. This rich blood supply allows for various reduction techniques, ensuring the viability of the skin flaps after 
surgery, Sensory innervation of the breast is dermatomal in nature. It is mainly derived from the anterolateral and anteromedial branches of thoracic intercostal nerves T3-T5. Supraclavicular nerves from the lower fibers of the cervical plexus also provide innervation to the upper and lateral portions of the breast, Researchers believe sensation to the nipple derives largely from the lateral cutaneous branch of $\mathrm{T} 4{ }^{(4)}$.The superior pedicle was described by Weiner et al. (5) and has traditionally been associated with smaller resections, best used in resections of less than 1000 gram, as it becomes difficult to inset with larger resections. It has been demonstrated to be a safe option in women with sternal notch to nipple distances more than $40 \mathrm{~cm}$. A major disadvantage of the superior pedicle technique is the higher risk for sensory loss at the nippleareolar complex postoperatively. This is found to be independent of the amount of tissue resected and is thought to be due to the tissue resection at the base of the breast this pedicle requires. Numbers as high as $70 \%$ of women have diminished sensation at the nipple-areolar complex 1 year postoperative with the superior pedicle, irrespective of the amount of tissue resected.

The inferior pedicle technique can reliably preserve the nipple-areola complex region well perfused in a breast of almost any size and shape. It is a technique that is easy to learn. Although it requires some flap undermining and the Wise pattern in most cases, it can be performed in 2-3 hours. Some feel that the inferior pedicle technique has a lower complication rate since the inferior location obliterates dead space in the dependent region of the breast. A major criticism of the inferior pedicle is the development of the "bottoming out" phenomenon $^{(6)}$.

The medial pedicle is sometimes described as a "superomedial" pedicle because it will often appear to be quite superior, especially with the more ptotic breast. Keeping some superior tissue does preserve vascularity, but retaining too much superior tissue will interfere with the ease of inset. The blood supply to the medial pedicle is provided by several smaller branches from the internal thoracic (mammary) system (third to sixth intercostal spaces). Since these vessels enter the breast at a superficial level, the pedicle can be either dermal or full thickness dermoglandular, On the other hand, nippleareola projection is less than that for the lateral pedicle technique ${ }^{(5)}$.The round block technique can be used in patients with small and moderate sized breasts without ptosis and for tumors located near the nipple areola complex but without nipple invasion. In this technique care must be taken to prevent injury to the dermis to preserve the blood supply of the nipple areola complex ${ }^{(7)}$.

Although, Traditional lumpectomy shown to be a good alternative to mastectomy for the appropriately selected breast cancer patients, it may result in poor cosmesis. Central oncoplastic techniques, including central lumpectomy, donut mastopexy lumpectomy, and variations of reduction mastopexy lumpectomy have been developed to address this problem. By combining largevolume tumor removal with breast-flap advancements, the oncoplastic techniques allow wider margins of resection and better breast shape and contour preservation ${ }^{(\mathbf{1})}$.

The lateral pedicle can be used in large breasts instead of the superior pedicle to avoid pedicle kinking. This pedicle has major advantages in terms of arterial input and breast sensation; branches from the lateral thoracic artery contribute to the blood supply, and the deep branches of the fourth intercostal nerve are incorporated, Septum-based lateral mammaplasty gives excellent results in terms of preservation of nipple- areola complex sensitivity and it is recommended for young patients who have exacting demands on preservation of nipple sensitivity ${ }^{(5)}$.

Increased viability of the NAC, a reduced rate of wound complications and preservation of sensation in NAC are the main advantages of this technique. Additionally, flattening of the NAC is avoided by the support by glandular tissue behind the NAC that improves projection and hereby the aesthetic conic appearance of both breast and nipple $^{(\mathbf{8})}$.

\section{Aim of the Work}

This study amed to focus on the laterocentral glandular pedicle technique as an oncoplastic procedure for management of medial breast cancer and to assess the technique clinically regarding oncological safety, surgical outcomes and patient satisfaction. 


\section{Patients and Methods}

\section{Type of the study}

This was a prospective analytical study that included 15 patients aiming to clinically assess the centro-lateral oncoplastic technique for both inner quadrants of breast cancer regarding oncological safety and patient satisfaction.

\section{Study settings}

This study was conducted at AinShams University Hospitals. Approval of the Ethical Committee and written informed consent from all participants was obtained.

Centro-lateral technique was proposed for patients in whom breast conservative treatment is possible on oncologic grounds but where a standard resection without reconstruction would lead to a poor cosmetic outcome. Diagnosis and staging examinations were carried out according to the standard protocol being conducted at Ain Shams University Hospitals

In-patient post-operative recovery time ranged from twenty four hours to a maximum of two days. All patients were discharged with a set of instruction and follow up schedule.

Patients of this study were all followed up for both oncologic and cosmetic grading and were referred to receive suitable adjuvant chemo and or radiotherapy according to the final pathology reported after conventional pathological evaluation.

Patient selection was achieved through a number of inclusion and exclusion criteria.

\section{Inclusion criteria}

Female patients with unilateral invasive breast cancer at upper and lower medial quadrantsfrom 18 to 60 years old and T1-T2 node positive patients.

\section{Exclusion criteria}

Distant metastasis, history of previously treated ipsilateral breast cancer, inflammatory tumors, T3 and T4 breast cancer, age less than 18 years, lesions involving or less than $1.5 \mathrm{~cm}$ from the nipple and areola, diffuse micro-calcification, patients demanding mastectomy for fear of local recurrence, patients not convinced with proposed procedure after adequate explanation and patients refusing post-operative adjuvant radiotherapy and patients with absolute contraindication to breast conserving surgery were carefully excluded from the study those showing wide spread micro calcifications or multicenteric breast cancer in more than one quadrant of the breast on mammography were candidates for conventional modified radical mastectomy, frozen section examination was done for each specimen to exclude a positive margin and determine the presence of intraductal component, patients with previously irradiated breast or having an absolute contraindication for adjuvant radiotherapy were excluded by their history.

All patients were submitted to history taking including full personal history, compliant, analysis of their disease along with thorough medical and family history with its relevance to the condition, complete clinical examination in the outpatient clinic.

\section{Results}

Table 1: mean age of the study

\begin{tabular}{|c|c|c|c|c|}
\hline & Mean & \pm SD & Minimum & Maximum \\
\hline Age & 45.70 & 9.27 & 18 & 60 \\
\hline
\end{tabular}

Table 2: number and percent of complications

\begin{tabular}{|l|r|c|c|}
\hline \multirow{2}{*}{ Comorbidity } & No & 12 & $80 \%$ \\
\cline { 2 - 4 } & Yes & 3 & $20 \%$ \\
\hline \multirow{3}{*}{$\begin{array}{l}\text { Type of } \\
\text { comorbidity }\end{array}$} & None & 12 & $80 \%$ \\
\cline { 2 - 4 } & DM & 1 & $6.6 \%$ \\
\cline { 2 - 4 } & HTN & 1 & $6.6 \%$ \\
\cline { 2 - 4 } & IHD & 1 & $6.6 \%$ \\
\hline
\end{tabular}

Table 3: number and percent of complications

\begin{tabular}{|l|r|c|c|}
\hline \multirow{2}{*}{ Comorbidity } & No & 12 & $80 \%$ \\
\cline { 2 - 4 } & Yes & 3 & $20 \%$ \\
\hline \multirow{3}{*}{$\begin{array}{l}\text { Type of } \\
\text { comorbidity }\end{array}$} & None & 12 & $80 \%$ \\
\cline { 2 - 4 } & DM & 1 & $6.6 \%$ \\
\cline { 2 - 4 } & HTN & 1 & $6.6 \%$ \\
\cline { 2 - 4 } & IHD & 1 & $6.6 \%$ \\
\hline
\end{tabular}

Table 4: mean tumor size in the study

\begin{tabular}{|r|c|c|c|c|}
\hline & Mean & \pm SD & Minimum & Maximum \\
\hline $\begin{array}{r}\text { U/s } \\
\text { Size }\end{array}$ & 2.00 & 0.47 & 1.00 & 3.2 \\
\hline
\end{tabular}

Table 5: the mean breast cup size for the study

\begin{tabular}{|r|r|r|r|r|}
\hline & Mean & \pm SD & Minimum & Maximum \\
\hline $\begin{array}{r}\text { Mean } \\
\text { Breasts } \\
\text { size }\end{array}$ & 3.33 & 1.56 & 1.00 & 7.00 \\
\hline
\end{tabular}


Table 6: mean distance of the tumor from NAC among patient population

\begin{tabular}{|r|c|c|c|c|}
\hline & Mean & \pm SD & Minimum & Maximum \\
\hline $\begin{array}{r}\text { Distance } \\
\text { from } \\
\text { NAC }\end{array}$ & 2.84 & 0.93 & 1.5 & 4.6 \\
\hline
\end{tabular}

Table 7: location of the tumor among patient population

\begin{tabular}{|l|c|c|}
\hline Tumor location & $\begin{array}{c}\text { Number of } \\
\text { patient }\end{array}$ & $\%$ \\
\hline Lower inner quadrant & 9 & $60 \%$ \\
\hline Upper inner quadrant & 6 & $40 \%$ \\
\hline
\end{tabular}

Table 8: mean operation time for our study

\begin{tabular}{|l|c|c|c|c|}
\hline & Mean & $\mathbf{\pm S D}$ & Minimum & Maximum \\
\hline $\begin{array}{l}\text { Operative } \\
\text { time }\end{array}$ & 107.60 & 14.50 & 90.00 & 155.00 \\
\hline
\end{tabular}

Table 9: mean $1^{\text {st }}$ day post-operative drain amount for the study

\begin{tabular}{|l|c|c|c|c|}
\hline & Mean & \pm SD & Minimum & Maximum \\
\hline $\begin{array}{l}\mathbf{1}^{\text {st }} \text { Day } \\
\text { Drain }\end{array}$ & 83.83 & 22.12 & 50.00 & 125.00 \\
\hline
\end{tabular}

Table 10: the mean post-operative stay for our study

\begin{tabular}{|l|c|c|c|c|}
\hline & $\begin{array}{c}\text { Mea } \\
\mathbf{n}\end{array}$ & $\begin{array}{c}\mathbf{\pm S} \\
\mathbf{D}\end{array}$ & $\begin{array}{c}\text { Minimu } \\
\mathbf{m}\end{array}$ & $\begin{array}{c}\text { Maximu } \\
\mathbf{m}\end{array}$ \\
\hline $\begin{array}{l}\text { Postoperativ } \\
\text { e stay }\end{array}$ & 30.00 & 8.77 & 24.00 & 72.00 \\
\hline
\end{tabular}

Table 11: number and percent of complications among patient population

\begin{tabular}{|c|c|c|c|}
\hline \multicolumn{2}{|c|}{ Complications } & No. & $\%$ \\
\hline Ulcer & $\begin{array}{l}\text { Negative } \\
\text { Positive }\end{array}$ & $\begin{array}{c}14 \\
1\end{array}$ & $\begin{array}{c}93.0 \% \\
7.0 \%\end{array}$ \\
\hline Infection & $\begin{array}{l}\text { Negative } \\
\text { Positive }\end{array}$ & $\begin{array}{c}13 \\
2\end{array}$ & $\begin{array}{l}87.0 \% \\
13.0 \%\end{array}$ \\
\hline
\end{tabular}

Table 12: postoperative pathological type of tumor among patient population

\begin{tabular}{|l|c|c|}
\hline $\begin{array}{c}\text { Postoperative pathological } \\
\text { Type of tumor }\end{array}$ & No & Percentage \\
\hline IDC & 11 & $74 \%$ \\
\hline ILC & 3 & $20 \%$ \\
\hline Mucinous carcinoma & 1 & $6 \%$ \\
\hline
\end{tabular}

Table 13: Mean cosmetic outcome for our study

\begin{tabular}{|l|c|c|c|c|}
\hline & Mean & \pm SD & Minimum & Maximum \\
\hline $\begin{array}{l}\text { Cosmetic } \\
\text { outcome }\end{array}$ & 4.23 & .86 & 2.00 & 5.00 \\
\hline
\end{tabular}

Table 14: number of cases for every score of cosmetic outcome

\begin{tabular}{|l|c|c|}
\hline Cosmetic outcome & No. & \% \\
\hline Score 5 & 10 & $66 \%$ \\
\hline Score 4 & 3 & $20 \%$ \\
\hline Score 3 & 1 & $6 \%$ \\
\hline Score 2 & 1 & $6 \%$ \\
\hline Score 1 & 0 & $0 \%$ \\
\hline Score 0 & 0 & $0 \%$ \\
\hline
\end{tabular}

\section{Discussion}

Breast cancer is cancer that develops from breast tissue. Signs of breast cancer may include a lump in the breast, a change in breast shape, dimpling of the skin, fluid coming from the nipple, or a red scaly patch of skin. In those with distant spread of the disease, there may be bone pain, swollen lymph nodes, shortness of breath, or yellow skin ${ }^{(9)}$. Oncoplastic breast surgery is based on three basic principles: ideal breast cancer surgery with wider excisions, immediate breast reconstruction, and immediate symmetry of the other breast whenever necessary. This is achieved through several techniques based on tumor location, characteristics of the breast, volume of mammary resection and clinical evaluation of the patient into volume displacement and volume replacement procedures. The volume displacement techniques use the remaining breast tissue, while the second, the volume replacement technique, uses other autologous tissue to supplement the insufficient breast tissue ${ }^{(\mathbf{1 0})}$.

With 1 million new cases in the world each year, Breast cancer is the commonest malignancy in women and comprises $18 \%$ of all female cancers. In the United Kingdom, where the age standardized incidence and mortality is the highest in the world, the incidence among women aged 50 approaches two per 1000 women per year, and the disease is the single commonest cause of death among women aged 40-50, accounting for about a fifth of all deaths in this age group. There are more than 14000 deaths each year, and the incidence is increasing particularly among women aged 50-64, probably because of breast screening in this age group ${ }^{(11)}$.

All of our patients had the tumor in lower outer and lower inner aspects of the breast except 2 patients (10\%) of the patients whom had the tumor in upper outer aspect, as upper outer quadrant is the most common site of breast cancer. 
In our study only 5 cases $(25 \%)$ have had complications, 3 cases got wound infection, two of them were diabetics reflecting the immune compromisation with diabetes mellitus. Statistically DM has increased the risk of post-operative wound infection thrice, this similar to what was published by $\boldsymbol{U}$ rban and Rietjens ${ }^{(1)}$ showing the complication of diabetes mellitus in oncoplastic surgery.

Those who had wound infection were treated with admission, parenteral antibiotics and frequent daily dressing with saline and topical antibiotics. The infection was eradicated within 2 to 3 days in one of the two patients and the patients were discharged on oral antibiotics with a more frequent follow up schedule, the second patient needed secondary suturing after treatment of the infection.

We reported lower results of surgical site infection (13\%) than reported by VilarCompte et al. ${ }^{(12)}(18.9 \%)$ and higher than reported by Olsen et al. ${ }^{(13)}$ (4.7\%).

Another case in our study had wound ulcer with an incidence rate $6 \%$, it was discovered in the $2^{\text {nd }}$ week post-operative. She did not have any other complications. For the patient the ulcer was a result of the heavy weight of the breast exerted on the skin of the breast even after reduction as the patient had breast cup size $\mathrm{G}$, patient was treated with topical antibiotics, topical re- epithelialization ointments and daily dressing until full recovery.None of the previously stated complications resulted in delay of postoperative adjuvant therapy and all patients were sent to receive their appropriate therapy according to schedule. The operative duration of our study was long at first (155 minutes) but with progression of our study and as we build up more experience the operating time was reduced to (90 minutes).

One of our last cases had long operative duration as the patient had breast cup size $\mathrm{G}$ which required large volume dissection.

In our study none of the patients had any malignant recurrence as confirmed by the pathologist in our multidisciplinary team proving that we had performed superior medial technique safely from oncological point of view. The follow up of the malignant recurrence was for the first six months as this was the time limitation of our study.In our study we were able to conduct an excellent cosmetic outcome for a relatively large tumor excisions with $66 \%$ of the cases (10 patients) falling in excellent and very good score groups with mean cosmetic outcome score 4.26. Another 20\% (3 cases) which fall in good and fair score groups as those two patients noticed asymmetry of the two breasts in front of the mirror as they refused bilateral breast reduction mastopexy. None of our cases have had a poor or an ugly score.

\section{Conclusion}

The combination of plastic surgery techniques with breast oncology surgery gives the surgeon a new tool for treatment of breast cancer. This approach has enabled us to increase the number and extend the indications of breast conserving surgery with wider margins offering safer oncologic control with more satisfactory cosmetic outcome. The choice of the oncoplastic technique is mainly based upon the location of the tumor, size of the breast and distance of the tumor from the nipple areola complex. So, all cases should be adequately reviewed in order to tailor the decisions for every single case.

\section{References}

1- Urban $C$ and Rietjens $M$ (2013): Oncoplastic and Reconstructive Breast Surgery.Springer-Verlag, $1^{\text {st }}$ edition. Italia.

2- Khaled H, Mikhail N, Kamel H et al. (2014): Cancer incidence in Egypt: results of the National Population-Based Cancer Registry Program. Journal of Cancer Epidemiology, 2014: 18-29.

3- Schrenk P (2015): Oncoplastic Breast Surgery .A Guide to Clinical Practice Springer-Verlag, $2^{\text {nd }}$ edition. Vienna. pp: 89-97

4- Maxwell GP and Gabriel A (2009): Breast Reconstruction. Aston SJ, Steinbrech DS, Walden JL. Aesthetic Plastic Surgery. Philadelphia, Pa: Elsevier.

5- Hamdi $M$ and Hall-Findlay EJ (2005): Vertical scar mammaplasty.In: Pedicle Choices in Breast Reduction, Springerverlag berlin Heidelberg, pp: 11-15.

6- Kronowitz S, Hunt $\mathrm{K}$, Kuerer $\mathrm{H}$ et al. (2007): Practical guidelines for repair of partial mastectomy defects using the breast reduction technique in patients undergoing breast conservation therapy. Plast. Reconstr. Surg., (120):1755-1763. 
7- Yang J, Bae S, Chung H et al. (2011): The usefulness of oncoplastic volume displacement techniques in the superiorly located breast cancers for Korean patients with small to moderatesized breasts. Ann. Plast. Surg., 67:474480

8- Phillip NB, Moustapha H, Karlien AV et al. (2003): Thelatero-central glandular pedicle technique forbreast reduction, British Journal of Plastic Surgery, 56(4): 358-361.

9- Saunders C and Jassal S (2015): Breast Cancer $.1^{\text {st }}$ ed. Oxford: Oxford University Press.

10- Yang $\mathrm{D}$, Lee $\mathrm{W}$, Cho $\mathrm{K}$ et al. (2012): Surgical techniques for personalized oncoplastic surgery in breast cancer patients with small-to moderate-sized breasts (part 1): volume displacement. Journal of Breast Cancer, 15(1):1-6.
11- Goldhirsch A, Wood W, Coates S et al. (2011): Strategies for subtypes dealing with the diversity of breast cancer: highlights of the St Gallen international expert consensus on the primary therapy of early breast cancer. Ann. Oncol.,22:1736-1747.

12- Vilar-Compte D, Rosales S, HernandezMello $N$ et al. (2009): Surveillance, control, and prevention of surgical site infections in breast cancer surgery: a 5year experience. American Journal of Infection Control., 37(8):674-679.

13- Olsen M, Chu-Ongsakul S, Brandt E et al. (2008): Hospital-associated costs due to surgical site infection after breast surgery. Archives of Surgery, 143(1):53-60. 